\title{
IMPLEMENTASI METODE LEAN SIX SIGMA PADA PRODUKSI WAJAN NOMOR 18 DI CV. XYZ
}

\author{
Siti Hardianti, Neva Satyahadewi, Nurfitri Imro'ah \\ INTISARI
}

\begin{abstract}
Pengendalian kualitas dapat dilakukan dengan berbagai cara, diantaranya menggunakan metode Lean Six Sigma. Metode Lean Six Sigma dapat menunjukkan jalannya proses produksi sehingga diketahui pemborosan, kecacatan dan proses terjadinya produksi melalui value stream mapping. Lean Six Sigma dapat diterapkan di bidang industri, satu diantaranya adalah perusahaan CV. XYZ. Perusahaan tersebut memproduksi wajan dengan nomor 10, 11, 12, 13, 14, 15, 16, 18, 20, 22, 24, 26, 28 dan 30. Wajan nomor 18 adalah wajan yang paling diminati konsumen. Tahapan dalam Lean Six Sigma dimulai dari define, measure dan analyze. Jenis kecacatan diklasifikasikan menjadi empat kelas yaitu sangat serius $(A)$, serius (B), cukup serius $(C)$ dan tidak serius $(D)$ dengan jumlah observasi sebanyak 78 hari. Kecacatan terbesar terjadi di kelas cacat sangat serius yaitu sebesar 44,38\%. Level sigma merupakan kemungkinan besar kecacatan yang akan terjadi jika memproduksi satu juta produk. Pada penelitian ini, level sigma yang dihasilkan kecacatan sangat serius adalah 3,2, sehingga dengan menggunakan nilai Defect Per Million Oppertunities (DPMO) dapat disimpulkan bahwa dalam satu juta produksi kemungkinan produk cacat sebesar 44.211 buah. Berdasarkan analisis Failure Mode and Effect Analyze (FMEA), diketahui penyebab kecacatan sangat serius dikarenakan material dengan nilai Risk Priority Number (RPN) sebesar 84. Sehingga dengan menggunakan kriteria penilaian RPN diketahui bahwa kecacatan yang disebabkan oleh material tergolong sedang.
\end{abstract}

Kata Kunci: Demerit, Failure Mode and Effect Analyze.

\section{PENDAHULUAN}

Kualitas merupakan keseluruhan ciri dan karakteristik produk atau jasa yang kemampuannya dapat memuaskan kebutuhan, baik yang dinyatakan secara tegas maupun samar [1]. Menurut Oakland (1993) faktor yang menentukan sukses tidaknya suatu usaha adalah kualitas, keandalan, harga dan pengiriman. Dari keempat faktor tersebut, kualitas adalah yang paling penting. Ketika suatu perusahaan fokus terhadap kualitas, maka secara otomatis tiga faktor lainnya juga mengalami peningkatan. Sehingga untuk menjaga agar kualitas suatu produk dapat meningkat diperlukan pengendalian kualitas. Pengendalian kualitas adalah suatu teknik dan aktivitas atau tindakan yang terencana yang dilakukan untuk mencapai, mempertahankan serta meningkatkan produksi (barang atau jasa) agar sesuai dengan standar yang ditetapkan [2].

Perusahaan CV. XYZ adalah salah satu perusahaan yang bergerak dalam bidang jasa produksi di kota Pontianak, Kalimantan Barat Indonesia. Perusahaan CV. XYZ menghasilkan produk diantaranya adalah wajan. Wajan merupakan salah satu peralatan dapur yang digunakan sebagai alat bantu memasak yang terbuat dari alumunium. Wajan yang diproduksi oleh perusahaan CV. XYZ ada berbagai macam nomor yaitu 10,11, 12, 13, 14, 15, 16, 18, 20, 22, 24, 26, 28 dan 30. Wajan nomor 18 adalah wajan yang sering diminati konsumen. Periode Juli-Desember 2017 perusahaan CV. XYZ memproduksi wajan nomor 18 sebanyak 8.844 buah dan terjadi cacat produk sebanyak 881 buah. Oleh karena itu diperlukan suatu metode pengendalian kualitas yang tepat agar dapat menekan jumlah produksi cacat yang terjadi dengan mengurangi pemborosan (waste). Salah satu metode pengendalian kualitas yang dapat mengatasi pengurangan jumlah cacat dengan mengurangi pemborosan adalah metode Lean Six Sigma. Metode ini merupakan kombinasi antara Lean dan Six Sigma.

Penelitian ini bertujuan untuk menganalisis pemborosan, menganalisis faktor-faktor penyebab kecacatan produk selama proses produksi berlangsung dan menganalisis level sigma yang dihasilkan. Hasil dari level sigma tersebut dapat digunakan untuk mengetahui berapa besar kecacatan yang terjadi. Berdasarkan klasifikasi kecacatan, data yang telah diperoleh dibuat statistik deskriptifnya terlebih dahulu, selanjutnya diidentifikasi dan digambarkan melalui Value Stream Mapping. Hal ini bertujuan 
untuk mengetahui proses produksi dari awal hingga akhir. Setelah itu dilakukan wawancara kepada karyawan maupun supervisor di perusahaan untuk mengetahui pemborosan yang terjadi selama produksi. Analisis uji Levene bertujuan untuk melihat apakah variansi data homogen. Jika variansi data homogen dilanjutkan dengan uji ANOVA, tapi jika tidak homogen dilanjutkan dengan uji Kruskal Wallis. Selanjutnya dilakukan uji Kolmogorov-Smirnov untuk mengetahui data berdistribusi Poisson, kemudian dibuat diagram kendali Demerit. Setelah data berada dalam batas kendali, dihitung nilai Defect Per Million Opportunities (DPMO) dan level sigma. Selanjutnya dicari penyebab kegagalan produk menggunakan Failure Mode and Effect Analyz dan membuat diagram Pareto untuk melihat jenis kegagalan terbesar hingga terkecil. Sehingga diperoleh nilai kemungkinan kecacatan yang terjadi jika memproduksi persejuta produk.

\section{LEAN SIX SIGMA}

Lean Six Sigma merupakan kombinasi antara Lean dan Six Sigma. Lean adalah suatu upaya terus menerus untuk menghilangkan pemborosan (waste) dan meningkatkan nilai tambah (value added) produk (barang dan jasa) agar memberikan nilai kepada pelanggan [3]. Jenis pemborosan diidentifikasi menjadi tujuh yaitu: produksi berlebih, kecacatan, penyimpanan yang tidak diperlukan, proses yang tidak tepat, transportasi yang berlebih, menunggu dan gerakan yang tidak diperlukan. Six Sigma adalah suatu visi peningkatan kualitas menuju target 3,4 kegagalan dalam persejuta kesempatan (DPMO) untuk setiap produksi (produk atau jasa) [4]. Lean Six Sigma merupakan sebuah metode pengendalian kualitas terhadap suatu produk (barang atau jasa) dengan menghilangkan pemborosan (waste) atau aktivitasaktivitas yang tidak bernilai tambah (non value added activities), melalui peningkatan terus menerus untuk mencapai tingkat kinerja six sigma [5].

\section{TAHAPAN LEAN SIX SIGMA}

Tahapan pertama yang dilakukan yaitu pendefinisian (define) dengan melakukan identifikasi produk yang digambarkan melalui value stream mapping dan mengidentifikasi pemborosan. Tahapan kedua yaitu pengukuran (measure) dengan melakukan uji homogenitas menggunakan uji Levene. Hipotesis uji Levene adalah:

$H_{0}: \sigma_{1}^{2}=\sigma_{2}^{2}=\cdots \sigma_{k}^{2}($ varians data homogen $)$

$H_{0}$ : paling tidak ada satu $\sigma_{i}^{2}$ yang tidak sama (varians data tidak homogen)

Statistik uji yang digunakan:

$$
w=\frac{(N-k) \sum_{i=1}^{k} n_{i}\left(\bar{Z}_{i .}-\bar{Z}_{. .}\right)^{2}}{(k-1) \sum_{i=1}^{k} \sum_{j=1}^{n_{i}}\left(Z_{i j}-\bar{Z}_{i .}\right)^{2}}
$$

Dengan $N$ adalah jumlah pengamatan, $k$ banyaknya jenis kecacatan, $\bar{Z}_{i \text {. }}$ adalah rata-rata kelompok dari $Z_{i j}$ dan $\bar{Z}_{. .}$adalah rata-rata menyeluruh dari $Z_{i j}$. Kriteria penerimaan yaitu $H_{0}$ diterima jika nilai $w<$ $F_{(\alpha ; k-1, n-k)}$ atau nilai $p$-value $>\alpha$ dengan $\alpha$ adalah tingkat kesalahan yang bisa ditoleransi [6].

Selanjutnya dilakukan uji Kruskal Wallis untuk mengetahui apakah terdapat perbedaan setiap kelas kecacatannya. Hipotesis uji Kruskal Wallis adalah:

$H_{0}$ : klasifikasi cacat mempunyai distribusi identik

$H_{1}$ : paling tidak ada satu klasifikasi kecacatan mempunyai distribusi tidak identik.

Statistik uji yang digunakan adalah:

$$
H=\frac{12}{N(N+1)} \sum_{i=1}^{k} \frac{R_{i}^{2}}{n_{i}}-3(N+1)
$$

Dengan $N$ adalah banyaknya observasi yang dilakukan, $k$ adalah banyaknya klasifikasi kecacatan, dan $R_{i}$ adalah jumlah rangking tiap klasifikasi kecacatan. Kriteria penerimaan yaitu $H_{0}$ diterima jika nilai $H<\chi_{(d k-1)}^{2}$ atau nilai $p$-value $>\alpha[7]$. 
Distribusi Poisson adalah distribusi probabilitas diskrit yang menyatakan peluang jumlah peristiwa yang terjadi pada periode waktu tertentu [8]. Pengujian data berdistribusi Poisson dapat dilakukan dengan uji Kolmogorov-Smirnov. Uji Kolmogorov-Smirnov merupakan suatu uji yang digunakan untuk melihat distribusi dari suatu data. Hipotesis yang digunakan untuk uji Kolmogorov-Smirnov yaitu:

$H_{0}$ : data berdistribusi Poisson

$H_{1}$ : data tidak berdistribusi Poisson

Statistik uji yang digunakan adalah:

$$
K S_{\text {hitung }}=\max \left|F_{0}(x)-F_{n}(x)\right|
$$

Dengan $F_{n}(x)$ adalah frekuensi kumulatif dari distribusi empiris dan $F_{0}(x)$ adalah frekuensi kumulatif yang dihitung menggunakan distribusi teoritis. Kriteria penerimaan yang digunakan yaitu $H_{0}$ terima jika $\mathrm{KS}_{\text {hitung }}<\mathrm{KS}_{\text {tabel }}$ atau $p$-value $\left.>\alpha\right)[9]$.

Selanjutnya membuat diagram kendali Demerit untuk mengetahui apakah proses sudah terkendali. Diagram kendali Demerit merupakan sistem yang mengklasifikasikan tingkat kecacatan suatu produk atau jasa, yang kemudian diberikan pembobotan pada karakteristik cacat tersebut sesuai dengan tingkat kepentingannya. Pembobotan dalam diagram kendali Demerit dibedakan menjadi empat, sesuai dengan klasifikasi kecacatan yaitu 100 untuk cacat sangat serius (A), 50 untuk cacat serius (B), 10 untuk cacat cukup serius (C) dan 1 untuk cacat tidak serius (D) [10].

Jumlah Demerit pada pengamatan ke- $i$ adalah:

$$
d_{i}=w_{A} C_{i A}+w_{B} C_{i B}+w_{C} C_{i C}+w_{D} C_{i D}
$$

dengan $w_{A}, w_{B}, w_{C}$ dan $w_{D}$ adalah bobot klasifikasi cacat A, B, C dan D. $C_{i A}, C_{i B}, C_{i C}$ dan $C_{i D}$ adalah kecacatan pada hari ke-i untuk klasifikasi cacat A, B, C dan D. Kecacatan per unit pada pengamatan ke$i$ adalah:

$$
u_{i}=\frac{d_{i}}{n_{i}}
$$

dengan $n_{i}$ adalah jumlah produksi pada pengamatan ke- $i$.

Garis tengah diagram kendali Demerit adalah:

$$
\bar{u}=w_{A} \bar{u}_{A}+w_{B} \bar{u}_{B}+w_{C} \bar{u}_{C}+w_{D} \bar{u}_{D}
$$

dengan $\bar{u}_{A}, \bar{u}_{B}, \bar{u}_{C}$, dan $\bar{u}_{D}$ adalah rata-rata jumlah kecacatan per unit pada klasifikasi cacat $\mathrm{A}, \mathrm{B}, \mathrm{C}$ dan D.

Rata-rata jumlah kecacatan per unit pada tiap klasifikasi adalah:

$$
\bar{u}_{A}=\sum_{i=1}^{m} \frac{c_{i A}}{n_{i}} ;=\sum_{i=1}^{m} \frac{c_{i B}}{n_{i}} ; \bar{u}_{C}=\sum_{i=1}^{m} \frac{c_{i C}}{n_{i}} ; \bar{u}_{D}=\sum_{i=1}^{m} \frac{c_{i D}}{n_{i}}
$$

Sehingga batas kendali Demerit 3 sigma adalah:

$$
\begin{aligned}
U C L_{i} & =\bar{u}+3 \hat{\sigma}_{u i} \\
C L & =\bar{u} \\
L C L_{i} & =\bar{u}-3 \hat{\sigma}_{u i}
\end{aligned}
$$

dan variansi Demerit pada pengamatan ke-i yaitu:

$$
\hat{\sigma}_{u i}=\left[\frac{(100)^{2} \bar{u}_{A}+(50)^{2} \bar{u}_{B}+(10)^{2} \bar{u}_{C}+\bar{u}_{D}}{n_{i}}\right]^{1 / 2}
$$

Rata-rata klasifikasi cacat A, B, C dan D dinyatakan dengan $\bar{u}_{A}, \bar{u}_{B}, \bar{u}_{C}$ dan $\bar{u}_{D}, n_{i}$ adalah jumlah unit yang diperiksa pada hari ke-i [11].

Defect Per Million Opportunities (DPMO) merupakan ukuran yang baik bagi kualitas produk ataupun proses, sebab berkorelasi langsung dengan kecacatan dan level sigma. Langkah menentukan nilai DPMO adalah [12]:

1. Mencari nilai Defect Per Unit (DPU)

$$
D P U=\frac{D}{U}
$$

2. Mencari nilai Total Opportunities (TOP) 


$$
T O P=O \times U
$$

3. Mencari nilai Defect per Opportunities (DPO)

4. Mencari nilai DPMO

$$
D P O=\frac{D}{T O P}
$$

$$
D P M O=D P O \times 1.000 .000
$$

dengan $D$ adalah jumlah kecacatan, $U$ adalah total produksi dan $O$ adalah jumlah produksi.

Setelah memperoleh nilai DPMO, selanjutnya dikonversikan ke nilai sigma dengan menggunakan Tabel Sigma atau dengan Persamaan 14:

$$
\text { Sigma }=\frac{x_{i}-\mu}{\sigma}\left(\frac{1-D P M O}{1.000 .000}\right)
$$

Setelah diperoleh level sigma, selanjutnya menganalisis penyebab kecacatan menggunakan Failure Mode and Effect Analysis (FMEA). FMEA adalah suatu prosedur terstruktur untuk mengidentifikasi dan mencegah sebanyak mungkin mode kegagalan. Langkah-langkah dalam menentukan FMEA adalah mencari rating terhadap severity, occurance, detection dan Risk Priority Number (RPN) proses produksi. Severity adalah yaitu menghitung seberapa besar dampak kejadian mempengaruhi proses produksi. Occurance merupakan kemungkinan bahwa penyebab kegagalan akan terjadi dan menghasilkan bentuk kegagalan selama masa produksi. Detection adalah pengukuran terhadap kemampuan mengendalikan kegagalan yang dapat terjadi. Penentuan nilai severity, occurance dan detection dimulai dari 1-10.

Setelah mendapatkan nilai severity, occurance dan detection maka akan diperoleh nilai RPN. RPN merupakan skor hasil kalkulasi yang menunjukan level resiko kegagalan, sehingga menjadi prioritas untuk ditingkatkan apabila skor RPN tertinggi. Hasil perhitungan nilai RPN didapatkan dari:

$$
R P N=S \times O \times D
$$

dengan $S$ adalah severity, $O$ adalah occurance dan $D$ adalah detection.

Kriteria RPN dapat dilihat pada Tabel 1.

Tabel 1 Kriteria RPN

\begin{tabular}{cc}
\hline Nilai RPN & Kriteria \\
\hline $0-19$ & Very Low \\
$20-79$ & Low \\
$80-119$ & Medium \\
$120-199$ & High \\
$>199$ & Very High \\
\hline
\end{tabular}

Tahapan terakhir dalam metode Lean Six Sigma adalah menghitung kecacatan terbesar hingga terkecil menggunakan diagram Pareto.

\section{STUDI KASUS}

Data yang digunakan adalah data produksi wajan nomor 18 di perusahaan CV. XYZ pada bulan JuliDesember tahun 2017 dengan jumlah produksi sebanyak 8.884 buah dan kecacatan produk sebanyak 881 buah. Berikut ini langkah-langkah dalam penyelesaian metode Lean Six Sigma:

1. Statistik Deskriptif

Gambaran mengenai data penelitian dapat dilihat pada Tabel 2.

\begin{tabular}{lcccc}
\hline \multicolumn{5}{c}{ Tabel 2 Statitsik Deskriptif } \\
\cline { 2 - 5 } & \multicolumn{5}{c}{ Klasifikasi Cacat } \\
\hline Sangat Serius (A) & Serius (B) & Cukup Serius (C) & Tidak Serius (D) \\
Minimum & 78 & 78 & 78 & 78 \\
Maksimum & 2 & 0 & 0 & 1 \\
Mean & 8 & 6 & 3 & 6 \\
Sum & 5 & 2 & 2 & 3 \\
\hline
\end{tabular}


Berdasarkan Tabel 2 diketahui bahwa klasifikasi kecacatan dibedakan menjadi empat yaitu klasifikasi cacat sangat serius, serius, cukup serius dan tidak serius, yang dinotasikan dengan A, B, C dan D. Jumlah pengamatan masing-masing klasifikasi kecacatan adalah 78 hari. Kecacatan terkecil dan terbesar pada klasifikasi cacat A adalah 2 dan 8, rata-rata kecacatan sebesar 5 buah dengan total kecacatan sebanyak 391. Klasifikasi cacat B terjadi kecacatan produksi sebesar 129, dengan kecacatan terkecil dan terbesar adalah 0 dan 6 sehingga memiliki rata-rata kecacatan sebanyak 2 buah setiap produksi. Klasifikasi cacat $\mathrm{C}$ terjadi kecacatan produksi sebesar 124 dengan kecacatan terkecil dan terbesar yaitu 0 dan 3, sehingga memiliki rata-rata kecacatan 2 buah setiap produksi. Serta kecacatan produksi pada klasifikasi cacat D adalah 237 dengan kecacatan terkecil dan terbesar yang terjadi yaitu 1 dan 6, sehingga rata-rata kecacatan produksi sebesar 3 buah.

2. Identifikasi Produk yang digambarkan melalui Value Stream Mapping.

Proses produksi wajan nomor 18 dimulai dari proses pencetakan, pengikiran, pembubutan, pelabelan dan diakhiri dengan proses packing. Wajan nomor 18 dicetak menggunakan cetakan yang terbuat dari tanah liat dan berbahan dasar alumunium. Wajan yang sudah dicetak kemudian dikikir menggunakan alat pengikir. Hal ini bertujuan untuk menghaluskan pinggiran wajan. Selanjutnya wajan dilakukan pembubutan menggunakan mesin pembubut, agar permukaan wajan lebih halus. Setelah itu dilakukan proses pelabelan, yaitu dengan membersihkan permukaan wajan menggunakan bensin dan diberi cap. Tahapan terakhir dalam proses ini adalah membungkus dan mengepak kuali menggunakan plastik dan diikat menggunakan kawat.

Secara keseluruhan proses pembuatan wajan nomor 18 dapat dilihat pada Gambar 1.

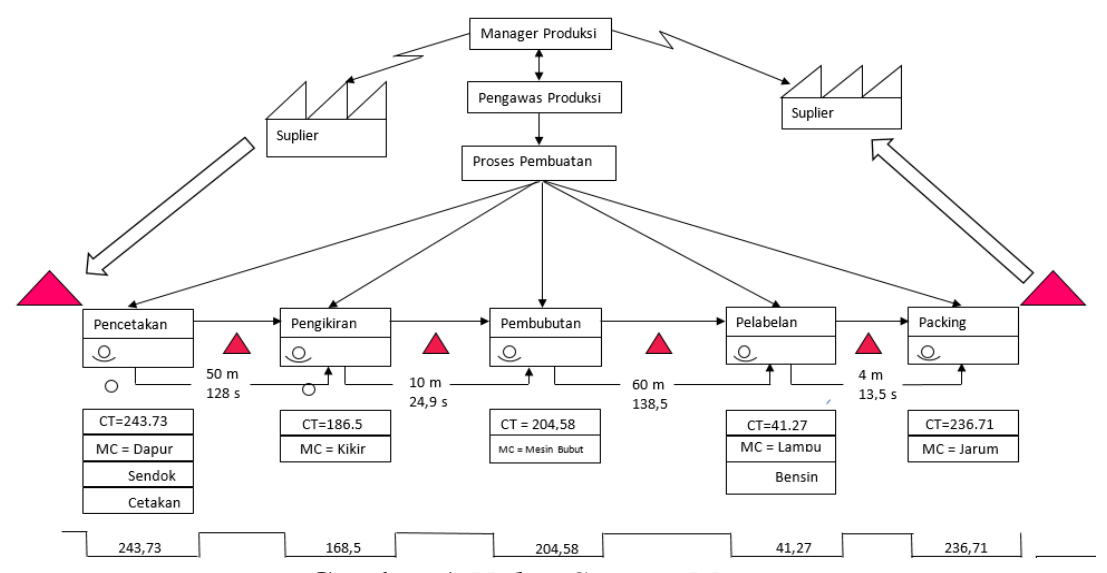

Gambar 1 Value Stream Mapping

3. Identifikasi Pemborosan

Identifikasi pemborosan diperoleh dari hasil wawancara kepada empat operator di perusahaan CV. XYZ, sehingga diperoleh hasil seperti Tabel 3.

Tabel 3 Identifikasi Pemborosan

\begin{tabular}{|c|c|c|c|c|c|c|c|}
\hline \multirow{2}{*}{ No. } & \multirow{2}{*}{ Jenis Pemborosan } & \multicolumn{4}{|c|}{ Operator } & \multirow{2}{*}{ Jumlah } & \multirow{2}{*}{ Keterangan } \\
\hline & & 1 & 2 & 3 & 4 & & \\
\hline 1 & Produksi berlebihan & 1 & 1 & 2 & 1 & 5 & Kadang-kadang terjadi \\
\hline 2 & Kecacatan & 2 & 2 & 1 & 2 & 7 & Sering terjadi \\
\hline 3 & Persediaan yang tidak penting & 0 & 0 & 0 & 0 & 0 & Tidak pernah terjadi \\
\hline 4 & Proses yang tidak tepat & 0 & 0 & 0 & 0 & 0 & Tidak pernah terjadi \\
\hline 5 & Transportasi yang berlebihan & 0 & 0 & 0 & 0 & 0 & Tidak pernah terjadi \\
\hline 6 & Waktu tunggu & 2 & 2 & 1 & 1 & 6 & Kadang-kadang terjadi \\
\hline 7 & Gerakan yang tidak berguna & 1 & 1 & 1 & 2 & 5 & Kadang-kadang terjadi \\
\hline
\end{tabular}

Kriteria penilaian yang digunakan dalam Tabel 3 yaitu nilai 0 artinya tidak pernah terjadi, nilai 1 artinya kadang-kadang terjadi, nilai 2 artinya sering terjadi, dan nilai 3 artinya selalu terjadi. Sehingga 
dari tabel tersebut diketahui bahwa jenis pemborosan yang terjadi selama proses produksi yaitu: produksi berlebih (kadang-kadang terjadi selama proses produksi), kecacatan (sering terjadi selama proses produksi), waktu tunggu (kadang-kadang terjadi selama proses produksi) dan gerakan yang tidak berguna (kadang-kadang terjadi selama proses produksi).

4. Uji Homogenitas

Uji homogenitas dalam penelitian ini menggunakan uji Levene. Hasil dari pengujian ini ditampilkan pada Tabel 4.

Tabel 4 Uji Levene

\begin{tabular}{lc}
\hline & Cacat \\
\hline P-value & 0,00 \\
Alpha & 0,05 \\
Kesimpulan & $H_{0}$ ditolak \\
\hline
\end{tabular}

Berdasarkan Tabel 4 diketahui bahwa variansi data tidak homogen, sehingga dilanjutkan dengan uji Kruskal Wallis.

\begin{tabular}{lc}
\multicolumn{2}{c}{ Tabel 5 Uji Kruskal Wallis } \\
\hline & Cacat \\
\hline P-value & 0,00 \\
Alpha & 0,05 \\
Kesimpulan & $H_{0}$ ditolak \\
\hline
\end{tabular}

Berdasarkan Tabel 5 diketahui bahwa sedikitnya ada satu klasifikasi cacat yang tidak identik dengan klasifikasi cacat lainnya, sehingga dapat dilanjutkan dengan uji Kolmogorov-Smirnov.

5. Diagram Kendali Demerit

Sebelum membuat diagram kendali Demerit, terlebih dahulu dilihat apakah data berdistribusi Poisson menggunakan uji Kolmogorov-Smirnov.

\begin{tabular}{lc}
\multicolumn{2}{c}{ Tabel 6 Uji Kolmogorv-Smirnov } \\
\hline$P$-value & Cacat \\
Alpha & 0,55 \\
Kesimpulan & 0,05 \\
\hline
\end{tabular}

Berdasarkan Tabel 6 diketahui bahwa data berdistribusi Poisson karena nilai p-value > alpha, sehingga dapat dilanjutkan dengan membuat diagram kendali Demerit. Proses pembuatan diagram kendali Demerit dimulai dari menghitung nilai kecacatan setiap observasi menggunakan Persamaan 4, sehingga diperoleh:

$$
\begin{aligned}
& d_{1}=((100 \times 4)+(50 \times 3)+(10 \times 2)+(1 \times 3))=573 \\
& d_{2}=((100 \times 6)+(50 \times 1)+(10 \times 2)+(1 \times 3))=673 \\
& \vdots \\
& d_{78}=((100 \times 2)+(50 \times 2)+(10 \times 2)+(1 \times 2))=322
\end{aligned}
$$

Selanjutnya menghitung kecacatan per-unit setiap observasi menggunakan Persamaan 5, sehingga diperoleh:

$$
\begin{aligned}
& u_{1}=\frac{((100 \times 4)+(50 \times 3)+(10 \times 2)+(1 \times 3))}{117}=4,897 \\
& u_{2}=\frac{((100 \times 6)+(50 \times 1)+(10 \times 2)+(1 \times 3))}{118}=5,703 \\
& \vdots \\
& u_{78}=\frac{((100 \times 2)+(50 \times 2)+(10 \times 2)+(1 \times 2))}{121}=2,661
\end{aligned}
$$


Selanjutnya menghitung rata-rata kecacatan menggunakan Persamaan 7 , sehingga diperoleh:

$$
\begin{aligned}
& \bar{u}_{A}=\frac{4+6+4+\ldots+4+3+2}{8.844}=0,044 \\
& \bar{u}_{B}=\frac{3+1+2+\ldots+2+1+2}{8.844}=0,015 \\
& \bar{u}_{C}=\frac{2+2+1+\ldots+2+1+2}{8.844}=0,014 \\
& \bar{u}_{D}=\frac{3+3+3+\ldots+3+4+2}{8.844}=0,027
\end{aligned}
$$

Selanjutnya menghitung nilai tengah diagram kendali Demerit menggunakan Persaman 6, sehingga diperoleh:

$$
\bar{u}=((100 \times 0,044)+(50 \times 0,014)+(10 \times 0,014)+(1 \times 0,026))=5,31739
$$

Setelah memperoleh nilai tengah diagram kendali Demerit, kemudian mencari nilai sigma setiap observasi dengan Persamaan 9, sehingga diperoleh:

$$
\begin{aligned}
& \sigma_{u_{1}}=\left[\frac{\left(\left(100^{2} \times 0,044\right)+\left(50^{2} \times 0,014\right)+\left(10^{2} \times 0,014\right)+\left(1^{2} \times 0,026\right)\right)}{117}\right]^{1 / 2}=2,025 \\
& \sigma_{u_{2}}=\left[\frac{\left(\left(100^{2} \times 0,044\right)+\left(50^{2} \times 0,014\right)+\left(10^{2} \times 0,014\right)+\left(1^{2} \times 0,026\right)\right)}{118}\right]^{1 / 2}=2,017 \\
& \vdots \\
& \sigma_{u_{8}}=\left[\frac{\left(\left(100^{2} \times 0,044\right)+\left(50^{2} \times 0,014\right)+\left(10^{2} \times 0,014\right)+\left(1^{2} \times 0,026\right)\right)}{121}\right]^{1 / 2}=1,992
\end{aligned}
$$

Setelah diperoleh nilai tengah dalam diagram kendali Demerit dan nilai sigma, kemudian dapat dihitung nilai $U C L$ dan $L C L$ setiap observasi menggunakan Persamaan 8. Salah satu perhitungan $U C L$ dan $L C L$ untuk observasi ke-1 yaitu:

$$
\begin{aligned}
& U C L_{1}=5,317+(3 \times 2,025)=11,394 \\
& L C L_{1}=5,317-(3 \times 2,025)=-0,759
\end{aligned}
$$

Bila $L C L_{i}$ yang dihasilkan bernilai negatif, maka nilai $L C L_{i}$ diubah menjadi 0 karena tidak ada jumlah cacat yang bernilai negatif. Berdasarkan perhitungan tersebut, diperoleh diagram kendali Demerit seperti Gambar 2.

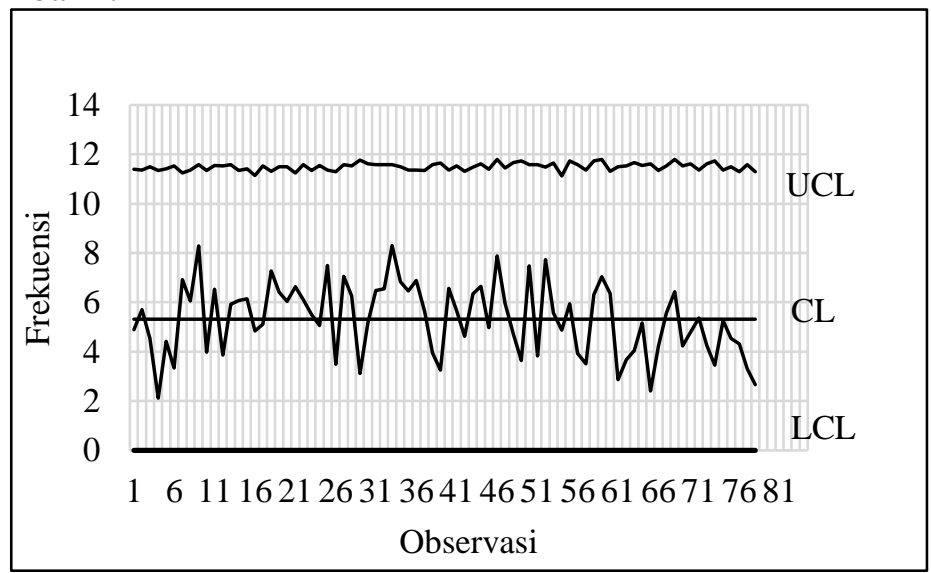

Gambar 2 Diagram Kendali Demerit

Berdasarkan Gambar 2 diketahui bahwa semua data sudah berada dalam batas kendali, sehingga dapat dilanjutkan ke tahapan selanjutnya.

6. DPMO dan Level sigma

Langkah pertama yaitu mencari nilai cacat per-unit (DPU) menggunakan Persamaan 10 pada masing-masing klasifikasi cacat. Selanjutnya mencari nilai total opportunities (TOP) menggunakan 
Persamaan 11. Setelah mendapatkan nilai DPU dan TOP selanjutnya mencari nilai defect per opportunities (DPO) dengan menggunakan Persamaan 12. Kemudian mencari nilai DPMO dengan Persamaan 13. Setelah diperoleh nilai DPMO, selanjutnya mencari level sigma dengan menggunakan Persamaan 14. Hasil perhitungan secara lengkap dapat dilihat pada Tabel 7.

Tabel 7 Nilai DPMO dan Level Sigma

\begin{tabular}{cccccccc}
\hline No & $\begin{array}{c}\text { Klasifikasi } \\
\text { Cacat }\end{array}$ & $\begin{array}{c}\text { Jumlah } \\
\text { Cacat }\end{array}$ & DPU & TOP & DPO & DPMO & $\begin{array}{c}\text { Level } \\
\text { Sigma }\end{array}$ \\
\hline 1 & A & 391 & 0,044 & 8.844 & 0,044 & $44.210,76$ & 3,2 \\
2 & B & 129 & 0,015 & 8.844 & 0,015 & $14.586,16$ & 3,7 \\
3 & C & 124 & 0,014 & 8.844 & 0,014 & $14.020,81$ & 3,7 \\
4 & D & 237 & 0,027 & 8.844 & 0,027 & $26.797,83$ & 3,4 \\
\hline & Total Cacat & 881 & 0,100 & 35.376 & 0,025 & $24.903,89$ & 3,5 \\
\hline
\end{tabular}

Berdasarkan Tabel 7 diketahui bahwa secara keseluruhan produk wajan nomor 18 memiliki level sigma sebesar 3,5, sehingga jika perusahaan CV. XYZ memproduksi wajan sebanyak satu juta produk, kemungkinan produk gagal sebesar 24.904 buah. Hal ini berdasarkan nilai DPMO yang diperoleh.

7. Failure Mode and Effect Analyze

Berdasarkan hasil penelitian terhadap pengawas operasional diperoleh bahwa penyebab kecacatan terjadi karena beberapa faktor, diantaranya seperti Tabel 8 berikut:

Tabel 8 Nilai Severity (S), Occurance (O), Detection (D) dan RPN

\begin{tabular}{|c|c|c|c|c|c|c|}
\hline $\begin{array}{l}\text { Penyebab } \\
\text { Kecacatan }\end{array}$ & Kegagalan & Efek Kegagalan & $\mathrm{S}$ & $\mathrm{O}$ & $\mathrm{D}$ & RPN \\
\hline Material & $\begin{array}{l}\text { Cairan alumunium } \\
\text { terlalu kental }\end{array}$ & $\begin{array}{l}\text { Alumunium cair yang } \\
\text { dihasilkan berwarna abu-abu } \\
\text { dan mengakibatkan adanya } \\
\text { penyok atau bolong pada } \\
\text { permukaan wajan }\end{array}$ & 7 & 4 & 3 & 84 \\
\hline Cetakan & Cetakan dingin & $\begin{array}{l}\text { Bentuk wajan nomor } 18 \text { tidak } \\
\text { sesuai dengan ketentuan } \\
\text { standar spesifikasi }\end{array}$ & 7 & 3 & 3 & 63 \\
\hline \multirow[b]{2}{*}{ Metode Kerja } & $\begin{array}{l}\text { Peleburan ingot belum } \\
\text { sempurna }\end{array}$ & $\begin{array}{l}\text { Permukaan wajan yang } \\
\text { dihasilkan tidak merata }\end{array}$ & 6 & 3 & 3 & 54 \\
\hline & $\begin{array}{l}\text { Standar Operasional } \\
\text { Prosedur (SOP) tertulis } \\
\text { belum ada }\end{array}$ & $\begin{array}{l}\text { Terjadi ketidak efisienan } \\
\text { proses produksi }\end{array}$ & 5 & 4 & 3 & 60 \\
\hline \multirow{3}{*}{ Manusia } & $\begin{array}{l}\text { Operator kurang terampil } \\
\text { dalam menguasai bidang } \\
\text { pekerjaannya }\end{array}$ & $\begin{array}{l}\text { Menghasilkan produksi wajan } \\
\text { yang tidak sesuai dengan } \\
\text { standar yang ditetapkan } \\
\text { perusahaan }\end{array}$ & 5 & 4 & 3 & 60 \\
\hline & $\begin{array}{l}\text { Karyawan Kelelahan } \\
\text { dalam bekerja }\end{array}$ & $\begin{array}{l}\text { Terdapat kecacatan produksi } \\
\text { wajan }\end{array}$ & 6 & 4 & 2 & 48 \\
\hline & $\begin{array}{l}\text { Kurang ketatnya } \\
\text { pengawas terhadap } \\
\text { proses produksi }\end{array}$ & $\begin{array}{l}\text { Terjadi ketidak efisienan } \\
\text { proses produksi }\end{array}$ & 4 & 5 & 2 & 40 \\
\hline \multirow{2}{*}{ Lingkungan } & $\begin{array}{l}\text { Tempat kerja masih } \\
\text { berantakan }\end{array}$ & $\begin{array}{l}\text { Terdapat produk wajan yang } \\
\text { cacat }\end{array}$ & 3 & 5 & 1 & 15 \\
\hline & $\begin{array}{l}\text { Alumunium cair bereaksi } \\
\text { dengan udara }\end{array}$ & $\begin{array}{l}\text { Terdapat produk wajan yang } \\
\text { cacat }\end{array}$ & 7 & 3 & 3 & 63 \\
\hline
\end{tabular}


Berdasarakan Tabel 8 penyebab terjadinya kecacatan terbesar (RPN tertinggi) disebabkan oleh material, cetakan, lingkungan dan seterusnya.

8. Diagram Pareto

Diagram Pareto dihitung dengan menghitung persentase setiap kelas cacatnya, kemudian dihitung nilai kumulatifnya sehingga diperoleh seperti Gambar 3.

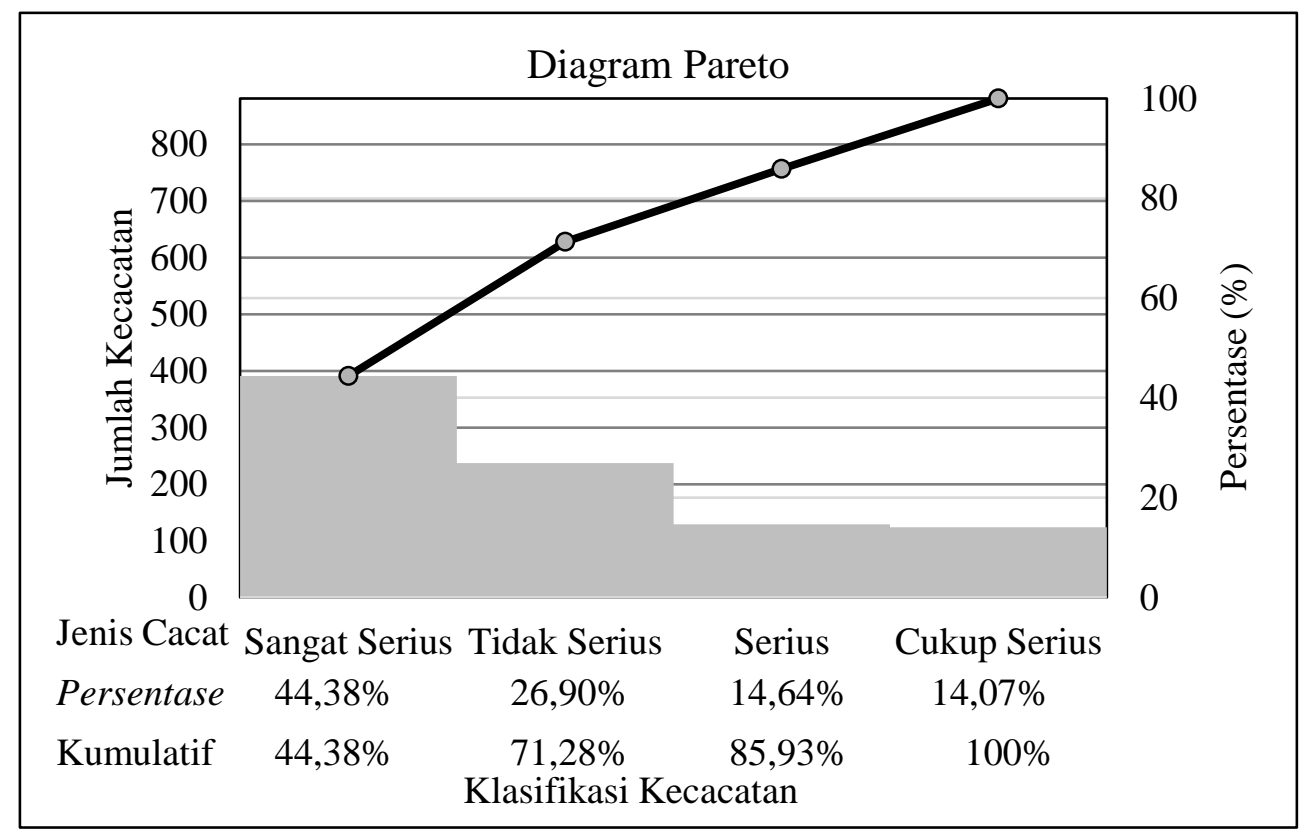

Gambar 3 Diagram Pareto

Berdasarkan Gambar 3 diketahui bahwa kecacatan terbesar yang terjadi pada wajan nomor 18 adalah kelas sangat serius (A) sebesar 391 buah dengan persentase sebesar $44,38 \%$.

\section{KESIMPULAN}

Kesimpulan yang diperoleh dari penelitian ini adalah:

1. Berdasarkan hasil penelitian, diketahui bahwa pemborosan yang terjadi selama proses produksi wajan nomor 18 adalah kecacatan, gerakan yang tidak diperlukan, menunggu dan produksi yang berlebih.

2. Level sigma pada proses produksi wajan nomor 18 adalah 3,5 dengan nilai DPMO sebesar 24.903,8. Hal ini berarti setiap memproduksi satu juta wajan nomor 18, kemungkinan terjadi kecacatan produksi sebesar $2,3 \%$.

3. Hasil Tabel FMEA menampilkan bahwa faktor penyebab kecacatan dengan kelas kecacatan tertinggi (cacat sangat serius) disebabkan oleh material dan cetakannya. Hal ini diketahui dengan perolehan nilai RPN sebesar 84 yang artinya kedua penyebab kecacatan tersebut tergolong sedang.

\section{DAFTAR PUSTAKA}

[1] Irwan, Hayono D. Pengendalian Kualitas Statistik. Bandung: Alfabet; 2015.

[2] Gasperz V. Total Quality Management. Jakarta: PT Gramedia Pustaka Utama; 2005.

[3] Gasperz V. Manajemen Kualitas Dalam Industri Jasa. Jakarta: PT. Gramedia Pustaka Utama; 2011.

[4] Gasperz V. Lean Six Sigma For Manufacturing and Service Industries. Jakarta: Gramedia Pustaka Utama; 2007.

[5] Gasperz V. Manajemen Kualitas Dalam Industri Jasa. Jakarta: Gramedia Pustaka Utama; 2011.

[6] Hartati A, Wuryandari T, Wilandari Y. Analisis Varian Dua Faktor Dalam Rancangan Pengamatan Berulang (Repeated Measures). Jurnal Gaussian. 2013; (4), 279-288. 
[7] Sugiono. Statistik Nonparametris. Bandung: Alfabet; 2015.

[8] Walpole RE. Pengantar Statistika. Jakarta: PT. Gramedia Pustaka Utama; 1992.

[9] Robianysah, Kusnandar D, Imro'ah N. Analisis Pengendalian Kualitas Produksi Crumb Rubber Dengan Metode Statistical Process Control. Jurnal Bimaster. 2018; (2), 93-100.

[10] Montgomery DC. Pengantar Pengendalian Kualitas Statistik [Soejoeti Z, trans]. Yogyakarta; Gadjah Mada University Press; 1990.

[11] Foresti K, Maiyastri, Adsi A. Penerapan Metode Six Sigma Pada Pengendalian Kualitas Air Kemasan Di PT. Gunung Naga Mas. Jurnal Matematika UNAND. 2018; (1), 93-102.

[12] Tannady H. Pengendalian Kualitas. Jakarta: Graha Ilmu; 2015.

SITI HARDIANTI NEVA SATYAHADEWI NURFITRI IMRO'AH
:FMIPA Untan Pontianak, siti.hardianti@student.untan.ac.id : FMIPA Untan Pontianak, neva.satya@math.untan.ac.id : FMIPA Untan Pontianak, nurfitriimroah18@gmail.com 